\title{
Henry Jenkins (2006), Confronting the Challenges of Participatory Culture: Media Education for the 21st Century, Chicago: The MacArthur Foundation
}

Eduardo Di Petta*

\author{
"The Revolution Will Not Be Televised" \\ Gil Scott Heron, 'poeta pai' do hip-hop
}

Não é dito se por questões ecológicas ou midiáticas, mas, para publicar este estudo de 72 páginas com nove capítulos, a norte-americana Fundação MacArthur optou pelo $e$-book, ao invés de cortar árvores. Disponível online e de graça. Isto para concluir cinco anos de pesquisas do seu e-learning, onde gastaram US\$ 50 milhões. Uma boa cifra do orçamento de 2,2 bilhões de receitas e um giro anual de US\$ 200 milhões da entidade, que foi buscar a mítica figura de Henry Jenkins, diretor do programa de estudos de mídia comparativa do MIT (Massachusetts Institute of Technology), para falar deste assunto sobre o qual todo mundo tem uma opinião, que já custou milhões aos cofres públicos de vários países, que está na ponta da discussão da União Européia, mas sobre o qual se avança a passos lentos: o uso das novas tecnologias nas escolas.

Salvadora ou apocalíptica? O estudo da fundação de Chicago atropela o grande dilema da era digital. Dá o fato como consumado, irreversível, e nos sugere as políticas necessárias para uma decolagem harmoniosa neste mundo e as habilidades que os futuros pilotos desta nave deverão adquirir para voar em céu de brigadeiro. É Darwin puro. Seleção natural na veia. Ou evoluímos para este mundo globalizado e hipermidiático, e nos incluímos na cultura digital, ou sobraremos náufragos, a deriva e a mercê dos grandes conglomerados da mídia e de sua indústria de entretenimentos e notícias. Para Jenkins, pais, escolas, entidades educadoras e governo precisam realizar um esforço conjunto para que todos possam ter acesso e treinamento a este mundo novo que já vem se desenhando. Para todos esses protagonistas, destina-se a obra, quase um manifesto da educação para os media ao raiar do século XXI.

Mas que mundo novo é este que interessa a Jenkins? Certamente, não é o individual, mas o coletivo. A que deu o nome de Cultura Participativa - e guia o título. Definição que se desdobra logo na primeira linha do sumário, onde Jenkins a define como: "uma cultura com relativamente poucas barreiras para expressões artísticas e engajamento cívico, imenso apoio para a criação e compartilhamento destas criações, alguns tipos de informações que os mais experientes passam aos mais novos e, também, aquela onde os membros acreditam que a sua contribuição importa, soma valor e o coneta" (p. 5).

Segundo Jenkins, ao participar suas culturas e conhecimentos, os jovens sentem-se socialmente conetados entre si, incluídos digitalmente, úteis para os seus pares e para a

* Doutorando em Ciências da Comunicação, Universidade do Minho, petta@agenciatie.com.br 
sociedade, como um dia o foram os jovens franceses em 1968, os portugueses em abril de 1974, a geração flower power norte-americana, os caras-pintadas do Brasil - e todos os jovens que um dia sonharam em fazer um mundo melhor.

Para surfar na onda da Cultura Participativa, Jenkins afirma que será preciso novas habilidades para, primeiro, formar a base, ficar de pé e, só depois, manobrar com segurança. Para criar os alicerces, o autor sugere a boa e velha literacia tradicional, azeitada no saber ler e escrever; no ver, enxergar e interpretar; na pesquisa técnica e na análise crítica. Tudo trabalhado em sala de aula, presencialmente. E aí sim, aprimorar-se nas novas habilidades - das quais tratará adiante. Só assim, para o autor, os jovens irão tornar-se comunitários, cooperativos e cidadãos participativos da sociedade.

Jenkins reporta que muitas escolas norte-americanas já estimulam este tipo de participação cultural como forma de trocar e ampliar experiências, que deverão ser (e penso que já são) valorizadas no mercado de trabalho, e também no empoderamento do conceito de cidadania. Mas há as escolas que não conseguem ou não querem ensinar; e os jovens que não conseguem ou não podem aprender. A brecha participativa é uma das três questões nucleares do desafio da divisão digital, largamente discutida por Jenkins. As outras duas são: a questão da transparência (o desafio dos jovens em face de aprender a como ver claramente os caminhos que os media tecem a percepção do mundo) e a da ética, que prevê uma quebra das formas tradicionais de treinamento profissional e de socialização a fim de preparar os jovens para participar da vida pública, tanto como realizadores midiáticos, como participantes comunitários.

Para Jenkins, fica claro que injetar novas tecnologias na sala de aula muda as relações com todas as outras formas de comunicação, tecnológicas ou não, como o quadro-negro, o lápis, os livros, papéis, etc. Mas, recomenda, e bem, o autor, que não devemos tratar estas tecnologias isoladamente, num olhar sociocêntrico, mas sim, observá-las pelo enfoque ecológico, pensando nas inter-relações tecnológicas e na interface destas com as comunidades culturais que vivem a sua volta - e as atividades que elas apoiam - em âmbitos políticos, sociais, económicos, legais e culturais.

Neste ponto, Jenkins filosofa, ao dizer que para culturas diferentes, diferentes ferramentas; assim como, diferentes ferramentas para diferentes culturas. E deixa claro que o presente estudo não foca na interatividade tecnológica, mas na participação cultural (popular). E assim aponta. "A interatividade é propriedade da tecnologia; já a participação, uma propriedade da cultura (da população) - uma participação que emerge da absorção e das respostas a cada novo media. E que só se desenvolve quando o senso se torna coletivo, e não individual” (p. 10).

Jenkins sabe bem que o uso da tecnologia não é inocente. A obra vem apoiada em forte bibliografia, aonde não faltam os pensadores de ponta da educação para os media, como os ingleses David Buckingham e Sonia Livingstone. Ele inclusive traz à tona o relatório da Kaiser Family Foundation (p. 13) com o tempo excessivo que os jovens gastam no ecrã, deixando de conviver em espaços públicos e reais, com sérias consequências para a saúde, ou do uso das máquinas sem a supervisão efetiva dos adultos sobre o que as crianças consomem neste mundo virtual - e o perigo que isto representa. Jenkins não nega estas ameaças, mas acha que focar no negativo é desviar do rumo, pais 
e professores, que deveriam seguir, ou melhor, pavimentar, o caminho para as crianças desenvolverem as habilidades necessárias para navegar na Cultura Participativa.

É o engate para o capítulo seguinte: "Porque devemos ensinar a educação para os media?", onde Jenkins desce do muro para defender com unhas e dentes a difusão da cultura participativa nas escolas, no ensino a distância e nas instituições de atividades extracurriculares - bem como nas casas dos alunos e colegas.

Começa então o pulo do gato. Em "O que devemos ensinar - repensando a literacia”, Jenkins faz do $e$-book, não um simples manifesto, mas algo para ser guardado e utilizado por todos aqueles que pretendem surfar nesta nova paisagem. Da página 24 a 54 , discorre sobre onze habilidades que os jovens devem adquirir. Habilidades sugeridas não alhures, mas fruto de uma longa pesquisa no corpo escolar formal e informal, recolhida nos últimos cinco anos. Para cada uma destas habilidades desejáveis, Jenkins tece comentários, dá exemplos de sucesso e sugere exercícios práticos com atividades criativas para os professores trabalharem em sala de aula, através de disciplinas tradicionais como história, ciências, matemáticas e literatura.

É uma surpresa agradável. Pois se a princípio estas habilidades parecem que irão recriar o mito do super-homem (Übermensch) impossível de Nietzsche, pela complexidade, principalmente para os migrantes tecnológicos, a suspeita vai se esfarelando com a leitura, ao notar que o treinamento das habilidades começa pela maneira mais simples que uma criança pode perceber o mundo: brincando. E que a partir de então, respeitando-se as idades da infância, ela pode ir evoluindo para outras habilidades, ainda de formas prazerosas como jogar, simular cidades, improvisar personalidades teatrais, reinterpretar obras, distribuir conhecimento, juntar-se a inteligência coletiva, navegar por diferentes medias, aprender a negociar, a respeitar as diferenças e a trabalhar em conjunto.

Em “Quem deve ser o responsável por ensinar?”, o capítulo seguinte, Jenkins recomenda: aos jovens, aprender com os sites de afinidades; aos professores, que se reciclem; às escolas, que se especializem, e aos políticos, que reflitam, pois a educação para os media não pode mais apresentar um caráter secundário no ensino. Neste mundo globalizado, hipermidiático, onde os media cada vez mais influenciam a nossa vida, ela deve ser tema central e essencial.

Faz ainda um apelo aos pais, para que também experimentem este mundo, para poderem compreender sobre seus riscos, oportunidades, armadilhas e, acima de tudo, para serem capazes de dialogar com seus filhos de maneira aberta, um contraponto ao "pai chato" que censura o fruto proibido - sempre o mais gostoso.

Finalmente, na conclusão, o autor toma emprestados os apontamentos de Bill Ivey, da National Endowment for the Arts e de Steven J. Tepper, da Vanderbilt University, (in Chronicle of Higher Education, 2006, cit. por Jenkins na p. 63), para dizer que, cada vez mais, quem tem acesso a educação, habilidades, recursos financeiros e tempo para navegar no oceano das escolhas culturais, terá acesso as novas oportunidade culturais e tenderá a ser o homem bem sucedido, engajado, apaixonado pelo que faz e acima de tudo curador da arte de sua própria vida, entendendo o mundo que o rodeia; ao passo que a parcela do menos: com menos tempo, menos habilidades, menos recursos, menos 
etc., estará, cada vez mais e mais, fadada a confiar nos meios de comunicação em massa, comandados pelos grandes conglomerados da mídia.

E o autor encerra a obra deixando algumas perguntas no ar. Para que estilo de vida caminha esta sociedade com cidadãos de vidas culturais tão distintas? Conseguirão as escolas educar os jovens em igualdade de oportunidade, em ambientes seguros, transparentes e éticos para que possam adquirir as habilidades necessárias para surfar a onda da Cultura Participativa? E eu questiono: revolução utópica? Para Henry Jenkins este é o grande desafio que defronta a educação (em todos os seus níveis) ao raiar desta nova era. E ele, ao menos, não está de braços cruzados a pensar no irritante dilema sobre o ser e não ser da tecnologia digital nas escolas. Afinal, se a revolução não vai ser televisionada, ela certamente passará pelo teu ecrã. 